\title{
Three Models to Analyze the Uncertainty of Boiler Emission Flue Gas Heat Loss
}

\author{
Jingxue An, Lei Wang, Jinwu Cheng, Youxin Li, Xuejiao Luo \\ China Datang Corporation Science and Technological Research Institute Co., Ltd, Central China branch, Zhengzhou 450000, \\ Henan, China \\ anjingxue@126.com
}

\begin{abstract}
Uncertainty assessment is a quantitative method about accuracy grade. This essay mainly focused on the principle of uncertainty analysis, including establish the uncertainty analysis model, assess the uncertainty components of type $A$ and type $B$, and calculate the sensitivity coefficient and combined standard uncertainty. Because the result is easy to go wrong when using partial differential to solve the sensitivity coefficient, two kinds of mathematical models without using partial differential are put forward. Based on the uncertainty assessment of boiler emission flue gas heat loss, three models are used to calculate the combined standard uncertainty of boiler flue gas heat loss respectively, the results are contrasted and analyzed which certified the correctness of the two new models. In this way, a new calculation method is bought up, as well as simplifying the work of uncertainty assessment.
\end{abstract}

Keywords-uncertainty; mathematical model; sensitivity coefficient; emission flue gas heat loss

\section{INTRODUCTION}

Generally, after the measurements and experimental work is achieved in the laboratory or on the scene, only the relevant test data are given in the test reports, but no description of the credibility of the test results is made. Strictly speaking, the testing effort is only half done, and the evaluation and analysis of test results is not conducted. Due to the existence of various uncertain factors, there is an error between the true value and the measured test data. Error analysis methods of the results are mostly used for error analysis. In recent years, uncertainty analysis error analysis has gradually replaced error analysis methods ${ }^{[1-2]}$, for evaluation of the test results. Uncertainty is the reliability of the measurement results to characterize reasonably be attributed to the dispersion of the measured values, it is a parameter containing the measurement results, it is possible to characterize the quality of the test results quantitatively. In general, the uncertainty, the higher the quality of the test results, the more advanced test level, the higher the value.

In recent years, error analysis method has been gradually replaced by uncertainty analysis for the evaluation of the test results. In 1993, a standard, Guide to the Expression of Uncertainty in Measurement (GUM), was issued by seven international organizations: the International Organization for Standardization (ISO), the International Electrotechnical Commission (IEC), BIPM (BIPM), the International Organization of Legal Metrology (OIML), the International Federation of physics and chemistry and Applied Chemistry (IUPAC), the International Federation of Clinical Chemistry (IFCC), the International Federation of Physical and
Chemical Physics and Applied Physics (IUPAPA). In 1995, GUM has been amended ${ }^{[3-4]}$. A unified standard for assessing, expressing and comparing the test results is provided by GUM with international common viewpoints and methods. In 1999, measurement specifications JJF10591999 "Measurement Uncertainty and Representation " is released by on the basis of GUM, used in place of JJF10271991 "measurement error and data processing" in the measurement error part.

\section{The PRINCIPLE OF UNCERTAINTY ANALYSIS}

\section{A. Mathematical Model}

Before the uncertainty analysis, a mathematical model which meets the requirement of the measurement uncertainty should be built. Here the measured parameters $Y$ is determined by a function of $n_{\text {inputs, }} X_{1}, X_{2} \ldots$ :

$$
Y=f\left(X_{1,} X_{2,} \cdots X_{n}\right)
$$

The mathematical model should meet the following requirements: (1) Include all input parameters that effect the measurement result. (2) No omission of any uncertainty components that effect the measurement result. (3) No repeat of any uncertainty components that effect the measurement result. (4) The model can be written into different forms when select different inputs.

\section{B. Assessment in Type A or Type B of Uncertainty}

The measurement uncertainty can be divided into type A and type B according to the assessment and expression.

- Measurement uncertainty assessment of type A

The type A uncertainty component $\left(u_{A}\right)$ is measured by statistical methods after $n$ times individual measurements. With $n$ times individual measurement of the measured parameter $x$ under the repeatability condition, the sample standard deviation $\left(s\left(x_{i}\right)\right.$ ) which characterizing the results of each measurement can be get using the Bessel formula:

$$
s\left(x_{i}\right)=\sqrt{\frac{\sum_{i=1}^{n} v_{i}^{2}}{n-1}}=\sqrt{\frac{\sum_{i=1}^{n}\left(x_{i}-\bar{x}\right)^{2}}{n-1}}
$$

And the standard uncertainty of the measurement is: 


$$
s(x)=\frac{s\left(x_{i}\right)}{\sqrt{n}}=\sqrt{\frac{\sum_{i=1}^{n}\left(x_{i}-\bar{x}\right)^{2}}{n \times(n-1)}}=u(x)
$$

- Measurement uncertainty assessment of type B

The assessment of type B uncertainty is mainly according to the following basis: (1) Previously observed data. (2) The experience and knowledge about the relevant technical materials and characteristic of the measurement instruments. (3) Documents from the production department. (4) Knowing of the acting rules of some influence factor on the system. (5) Data, accuracy class and levels from calibration certificate, test certificate or other documents, including the limit error currently in use. (6) Reference data and uncertainty from manual or some material. (7) The repeatability limit $r$ and reproducibility limit $R$ from national standards or technical documents that prescribes the test methods.

By the method above we get the $u\left(x_{i}\right)$, named measurement uncertainty of type B.

- Combined measurement uncertainty assessment

When the measurement result $f$ is measured indirectly with several inputs $x_{i}$ which are independent or uncorrelated, the combined standard uncertainty $u_{c}(y)$ can be obtained from this formula:

$$
u_{c}(y)=\left[\sum_{i=1}^{n}\left(\frac{\partial f}{\partial x_{i}}\right)^{2} u^{2}\left(x_{i}\right)\right]^{1 / 2}=\left[\sum_{i=1}^{n} c_{i}^{2} u^{2}\left(x_{i}\right)\right]^{1 / 2}
$$

$$
\text { Here the } c_{i}=\frac{\partial f}{\partial x_{i}} \text {, named as sensitivity coefficient is a }
$$
partial derivative of the function $f$ with respect to $x_{i}$.

- Extend measurement uncertainty assessment

The extend measurement uncertainty $U$ is expressed by the multiples of the combined standard uncertainty. Here $U$ is a numerical scale in a scale of $[y-U, y+U]$ the probability is high enough to cover most of the measurement results. For comparison we extend to a confidence level of about $95 \%$, normally include the factor $k=2$ [5-6]:

$$
U=k u_{c}
$$

Wherever Times is specified, Times Roman or Times New Roman may be used. If neither is available on your word processor, please use the font closest in appearance to Times. Avoid using bit-mapped fonts if possible. True-Type 1 or Open Type fonts are preferred. Please embed symbol fonts, as well, for math, etc.

\section{The Simplified AsSESSMENT OF THE COMBINED STANDARD UNCERTAINTY}

In the assessment process throughout the measurement uncertainty, the key part is to calculate the combined standard uncertainty, combined standard uncertainty required sensitivity coefficient is calculated, and the sensitivity coefficient required to solve partial differential, if more complex mathematical model, with partial differential calculation is too much trouble, prone to error, this paper proposes two methods to avoid solving partial differential, a relative standard uncertainty method, a method for the numerical interference. Analyze specific issues, you can choose different calculation model based on the actual problem. This paper utilizes three methods of heat losses uncertainty were assessed and compared.

\section{A. Method of Obtaining the Relative Standard Uncertainty}

Using the relative standard uncertainty, the combined standard uncertainty model can be simplified into three simpler model: the linear model only involves the sum or difference, the model involves only the product or quotient and the complex model.

- Definition of the relative standard uncertainty

The relative standard uncertainty is the key to solve the combined standard uncertainty $u_{r e l}\left(x_{i}\right)$. So here introducing its definition as a ratio of a variable's uncertainty and the variable itself. The relationship is:

$$
u_{r e l}\left(x_{i}\right)=\frac{u\left(x_{i}\right)}{x_{i}}
$$

- For the linear model only involves the sum or difference

For the linear model with a functional form only involves the sum or difference such as $y=c_{1} x_{1}+c_{2} x_{2}+\cdots c_{n} x_{n}$, the combined standard uncertainty is:

$$
u_{c}(y)=\sqrt{c_{1}^{2} u^{2}\left(x_{1}\right)+c_{2}^{2} u^{2}\left(x_{2}\right)+\cdots c_{n}^{2} u^{2}\left(x_{n}\right)}
$$

For this kind of model, a method of sum and root can be applied to get the result.

- For the model involves only the product or quotient

For the linear model with a functional form only involves the product or quotient such as $y=m x_{1}^{r_{1}} x_{2}^{r_{2}} \cdots x_{n}^{r_{n}}$, the combined standard uncertainty is:

$$
u_{r e l}(y)=\frac{u_{c}(y)}{y}=\sqrt{\sum_{i=1}^{n}\left[r_{i} \frac{u\left(x_{i}\right)}{x_{i}}\right]^{2}}=\sqrt{\sum_{i=1}^{n}\left[r_{i} u_{r e l}\left(x_{i}\right)\right]^{2}}
$$

In this formula, $m$ is a constant and the exponent $r_{i}$ can be positive or negative (ignoring the uncertainty of 
$\left.r_{i}\right) . u_{r e l}\left(x_{i}\right)=\frac{u\left(x_{i}\right)}{x_{i}}$ is the relative standard uncertainty whose sensitivity coefficient $\left|c_{i}\right|=\left|r_{i}\right|$.

$$
u_{c}(y)=y \sqrt{\sum_{i=1}^{n}\left[r_{i} u_{r e l}\left(x_{i}\right)\right]^{2}}
$$

- $\quad$ For the complex model

The function of the complex model is over the limit of formula (7) and (8). It contains both the sum and difference part and the product and quotient part. Here is an example: $y=\frac{x_{1}+x_{2}}{x_{3}}$. When dealing with the combining of the uncertainty component in this model, we can decompose the original mathematical model for convenience. For example decompose $y=\frac{x_{1}+x_{2}}{x_{3}}$ into $x_{1}+x_{2}$ and $x_{3}$ so that the principle one or two can now be applied. Then by principle one we can obtain the temporary uncertainty of each part and by principle two we combined these temporary uncertainties together into the combined standard uncertainty.

$$
\begin{aligned}
& u_{r e l}(y)=\frac{u_{c}(y)}{y}=\sqrt{\left[\frac{u\left(x_{1}+x_{2}\right)}{x_{1}+x_{2}}\right]^{2}+\left[\frac{u\left(x_{3}\right)}{x_{3}}\right]^{2}} \\
& =\sqrt{\left[\frac{\sqrt{u\left(x_{1}\right)^{2}+u\left(x_{2}\right)^{2}}}{x_{1}+x_{2}}\right]^{2}+\left[\frac{u\left(x_{3}\right)}{x_{3}}\right]^{2}}
\end{aligned}
$$

\section{B. Numerical Method of Perturbation}

As the calculation of the sensitivity coefficient is very complicated, someone suggested that [7] using the numerical method of perturbation to estimate the value in the calculation of combined standard uncertainty. Assume a variables $x_{i}$ corresponding to a calculation value of $f_{1}$, when $x_{i}$ changes a bit $\Delta x$ (normal set as $1 \%$ of $x_{i}$ ), $f_{1}$ changes to $f_{2}$. So the sensitivity coefficient can be calculated as:

$$
c_{1}=\left|\frac{f_{1}-f_{2}}{\Delta x}\right|
$$

\section{Standard Uncertainty Of BoIler Flue Gas HeAt Loss CALCULATION}

Boiler emission heat loss is an indirect measurement values, involving the direct measurement of multiple parameters, for example, boiling coal composition, emission flue gas temperature, emission flue gas oxygen content, atmospheric pressure, atmospheric temperature and humidity, flue gas heat and water vapor heat. Therefore the assessment of uncertainty to boiler emission flue gas heat loss is a complicated process. Three uncertainty assessment method is used to assess the uncertainty. Assumption: the known

\begin{tabular}{|c|c|c|}
\hline Measured Parameters & value & uncertainty \\
\hline As received basis carbon $(\%)$ & 44. 15 & 0.43 \\
\hline As received basis hydrogen $(\%)$ & 2.37 & 0.15 \\
\hline As received basis nitrogen $(\%)$ & 0.76 & 0.09 \\
\hline As received basis oxygen $(\%)$ & 3.85 & 1.11 \\
\hline As received basis sulphur $(\%)$ & 0.56 & 0.06 \\
\hline $\begin{array}{l}\text { As received basis total moisture } \\
\qquad(\%)\end{array}$ & 11.2 & 0.27 \\
\hline As received basis ash $(\%)$ & 37.11 & 0.97 \\
\hline Lower heating value $(\mathrm{kJ} / \mathrm{kg})$ & 15860 & 135 \\
\hline Fly ash proportion $(\%)$ & 90 & 5 \\
\hline Fly ash combustible content ( $\%)$ & 1.56 & 0.3 \\
\hline Slag proportion $(\%)$ & 10 & 5 \\
\hline Slag combustible content (\%) & 3.84 & 0.39 \\
\hline Emission flue gas temperature $\left({ }^{\circ} \mathrm{C}\right)$ & 134.8 & 2.4 \\
\hline oxygen content oxygen content $(\%)$ & 4.5 & 0.4 \\
\hline Air temperature $\left({ }^{\circ} \mathrm{C}\right)$ & 28.2 & 0.7 \\
\hline absolute humidity of air $(\mathrm{kg} / \mathrm{kg})$ & 0.01 & 0.001 \\
\hline $\begin{array}{l}\text { Dry flue gas Specific heat } \\
\qquad(\mathrm{kJ} / \mathrm{m} 3 . \mathrm{k})\end{array}$ & 1.38 & 0.04 \\
\hline Specific heat $\left(\mathrm{kJ} / \mathrm{m}^{3} \cdot \mathrm{k}\right)$ & 1.58 & 0.05 \\
\hline
\end{tabular}
conditions shown in Table I has been a type A and type B assessment.

TABLE I. KNOWN CONDITIONS OF UNCERTAINTY ASSESSMENT

On the base of GB10184-88 and the principle of boiler ${ }^{[8]}$, Emission flue gas heat loss can be calculated as follow:

TABLE II. MAIN CALCULATION FORMULA

\begin{tabular}{|l|l} 
Calculated Parameters & Calculation formula
\end{tabular}




\begin{tabular}{|c|c|}
\hline $\begin{array}{l}\text { Average ash carbon } \\
\text { content }(\%)\end{array}$ & $\bar{C}=\frac{a_{\mathrm{z}} C_{\mathrm{z}}}{100-C_{l z}}+\frac{a_{j n} C_{j h}}{100-C_{j h}}$ \\
\hline $\begin{array}{l}\text { Actual burned carbon } \\
\text { content }(\%)\end{array}$ & $C_{r}=C_{a r}-\frac{A_{a r} \bar{C}}{100}$ \\
\hline Excess air coefficient & $\alpha_{p y}=\frac{21}{21-O_{2}}$ \\
\hline $\begin{array}{l}\text { Theoretical dry air flow } \\
(\mathrm{m} 3 / \mathrm{kg})\end{array}$ & $\begin{array}{l}V_{g^{k}}^{0}=0.089\left(C_{r}+0.375 S_{a r}\right) \\
+0.265 H_{a r}-0.0333 O_{a r}\end{array}$ \\
\hline $\begin{array}{l}\text { Theoretical dry flue gas } \\
\text { flow }(\mathrm{m} 3 / \mathrm{kg})\end{array}$ & $\begin{array}{l}V_{g y}^{0}=1.866 \frac{C_{r}+0.375 S_{a r}}{100} \\
+0.79 V_{g k}^{0}+0.8 \frac{N_{a x}}{100}\end{array}$ \\
\hline $\begin{array}{l}\text { Actual dry flue gas flow } \\
(\mathrm{m} 3 / \mathrm{kg})\end{array}$ & $V_{g y}=V_{g y}^{0}+\left(a_{p y}-1\right) V_{g \hbar}^{0}$ \\
\hline $\begin{array}{l}\text { Steam volume in the } \\
\text { flue gas }\left(\mathrm{m}^{3} / \mathrm{kg}\right)\end{array}$ & $\begin{array}{l}V_{H_{2} O}=1.24\left(\frac{9 H_{a r}+M_{a r}}{100}\right. \\
\left.+1.293 a_{p y} V_{g h r}^{0} d_{k}\right)\end{array}$ \\
\hline $\begin{array}{c}\text { Emission flue gas heat } \\
\operatorname{loss}(\mathrm{kJ} / \mathrm{kg})\end{array}$ & $\begin{array}{l}q_{2}=\frac{V_{g y} C_{p, g y}\left(t_{p y}-t_{0}\right)}{Q_{n e t, a r}} \\
+\frac{V_{H_{2} O} C_{p, H_{2} O}\left(t_{p y}-t_{0}\right)}{Q_{n e t, a r}}\end{array}$ \\
\hline
\end{tabular}

According to the above formula, first, in order to solve the uncertainty of boiler emission flue gas heat loss, the original method of definition is used. After that both relative standard uncertainty and numerical perturbation method are used to calculate the uncertainty and make a comparison.

The combined standard uncertainty of average ash carbon content $u_{c}(\bar{C})$ is calculated as an example.

- By using partial differential procedure, the uncertainty $u_{c}(\bar{C})$ can be expressed as follows:

$$
\begin{aligned}
& u_{c}^{2}(\bar{C})=c_{\alpha_{f h}}^{2} u_{c}^{2}\left(\alpha_{f h}\right)+c_{\alpha_{l z}}^{2} u_{c}^{2}\left(\alpha_{l z}\right) \\
& +c_{C_{f h}}^{2} u_{c}^{2}\left(C_{f h}\right)+c_{C_{l z}}^{2} u_{c}^{2}\left(C_{l z}\right) \\
& =\left(\frac{C_{f h}}{100-C_{f h}}\right)^{2} u_{c}^{2}\left(\alpha_{f h}\right)+\left(\frac{C_{l z}}{100-C_{l z}}\right)^{2} u_{c}^{2}\left(\alpha_{l z}\right) \\
& +\left[\frac{100 \alpha_{f h}}{\left(100-C_{f h}\right)^{2}}\right]^{2} u_{c}^{2}\left(C_{f h}\right)+\left[\frac{100 \alpha_{l z}}{\left(100-C_{l z}\right)^{2}}\right]^{2} u_{c}^{2}\left(C_{l z}\right)
\end{aligned}
$$

Where $c_{a_{f h}}, c_{a_{l z}}, c_{c_{f h}}$ and $c_{c_{l z}}$ stand for fly ash quantity, slag quantity, carbon content in fly ash, the sensitivity coefficients of carbon content in fly ash, respectively. The result of calculation is:

$$
\begin{aligned}
& \bar{C}=1.83 \% \\
& u_{c}(\bar{C})=0.354 \%
\end{aligned}
$$

- Calculate the sensitivity coefficient using the perturbation method. Here set the perturbation as $1 \%$ of the variable. The results are:

$$
\begin{gathered}
c_{\alpha_{f h}}=0.01585 c_{\alpha_{l z}}=0.03993 \\
c_{C_{f h}}=0.9289 c_{C_{l z}}=0.1082 \\
u_{c}^{2}(\bar{C})=c_{\alpha_{f h}}^{2} u_{c}^{2}\left(\alpha_{f h}\right)+c_{\alpha_{l z}}^{2} u_{c}^{2}\left(\alpha_{l z}\right) \\
+c_{C_{f h}}^{2} u_{c}^{2}\left(C_{f h}\right)+c_{C_{l z}}^{2} u_{c}^{2}\left(C_{l z}\right)
\end{gathered}
$$

So $u_{c}(\bar{C})=0.354 \%$.

Calculating using relative standard uncertainty method. Because the function here contains product and quotient, we use the complex mode in the relative standard uncertainty calculation. Set that: $y_{1}=\frac{\alpha_{l z} C_{l z}}{100-C_{l z}} \quad y_{2}=\frac{\alpha_{f h} C_{f h}}{100-C_{f h}}$.

So

$$
\begin{aligned}
& u_{c}\left(y_{1}\right)=\alpha_{l z} C_{l z} u_{r e l}\left(\alpha_{l z} C_{l z}\right)= \\
& \alpha_{l z} C_{l z} \sqrt{\left[\frac{u\left(\alpha_{l z}\right)}{\alpha_{l z}}\right]^{2}+\left[\frac{u\left(C_{l z}\right)}{C_{l z}}\right]^{2}} \\
& u_{c}\left(y_{1}\right)=y_{1} u_{r e l}\left(y_{1}\right)= \\
& \frac{\alpha_{l z} C_{l z}}{100-C_{l z}} \sqrt{\left[\frac{u_{c}\left(\alpha_{l z} C_{l z}\right)}{\alpha_{l z} C_{l z}}\right]^{2}+\left[\frac{u\left(C_{l z}\right)}{\left(100-C_{l z}\right)}\right]^{2}} \\
& \text { By the same way: } u_{c}\left(\alpha_{f h} C_{f h}\right) \text { 与 } u_{c}\left(y_{2}\right) .
\end{aligned}
$$

$$
\begin{aligned}
& u_{c}(\bar{C})=\sqrt{u_{c}^{2}\left(y_{1}\right)+u_{c}^{2}\left(y_{2}\right)} \\
& \text { The result is: } \quad u_{c}(\bar{C})=0.351 \%
\end{aligned}
$$

The calculation above tells that the two new method of combined standard uncertainty have reasonable error with the original method using the definition. Using these three methods to assess the standard uncertainty in the heat loss in the smoke extracting gives the result table blow. 
TABLE III. RESUlt Of UNCERTAINTY OF BOILER EMISSION FLUE GAS HEAT LOSS

\begin{tabular}{|c|c|c|c|c|}
\hline \multirow{2}{*}{$\begin{array}{c}\text { Calculated } \\
\text { Parameters }\end{array}$} & Value & \multicolumn{3}{|c|}{ Uncertainty } \\
\cline { 3 - 5 } & definition & $\begin{array}{c}\text { numerical } \\
\text { perturbation } \\
\text { method }\end{array}$ & $\begin{array}{c}\text { relative } \\
\text { standard } \\
\text { uncertainty }\end{array}$ \\
\hline $\begin{array}{c}\text { Average ash } \\
\text { carbon content } \\
(\%)\end{array}$ & 1.83 & 0.354 & 0.354 & 0.351 \\
\hline $\begin{array}{c}\text { Actual burned } \\
\text { carbon content } \\
(\%)\end{array}$ & 43.47 & 0.450 & 0.450 & 0.448 \\
\hline $\begin{array}{c}\text { Excess air } \\
\text { coefficient }\end{array}$ & 1.27 & 0.031 & 0.031 & 0.031 \\
\hline $\begin{array}{c}\text { Theoretical dry } \\
\text { air flow } \\
\left(\mathrm{m}^{3} / \mathrm{kg}\right)\end{array}$ & 4.387 & 0.073 & 0.073 & 0.073 \\
\hline $\begin{array}{c}\text { Theoretical dry } \\
\text { flue gas flow } \\
(\mathrm{m} 3 / \mathrm{kg})\end{array}$ & 4.287 & 0.111 & 0.111 & 0.111 \\
\hline $\begin{array}{c}\text { Actual dry flue } \\
\text { gas flow } \\
\left(\mathrm{m}^{3} / \mathrm{kg}\right)\end{array}$ & 5.471 & 0.177 & 0.177 & 0.177 \\
\hline $\begin{array}{c}\text { Steam volume } \\
\text { in the flue gas } \\
\left(\mathrm{m}^{3} / \mathrm{kg}\right)\end{array}$ & 0.473 & 0.019 & 0.019 & 0.020 \\
\hline $\begin{array}{c}\text { Emission flue } \\
\text { gas heat loss } \\
(\mathrm{kJ} / \mathrm{kg})\end{array}$ & 5.58 & 0.257 & 0.257 & 0.261 \\
\hline
\end{tabular}

The value of all uncertainties is calculated by the definition method.

According to the calculations, not only the principle of numerical perturbation method is consistent with partial differential method, but also the calculation result is equal, moreover, numerical perturbation method was able to avoid for solving partial differential and simplifying calculation. The calculation error of relative standard uncertainty method and the partial differential method is so small that can be ignored, however, there is a little deviation when assessing the uncertainty about multivariate multiplied. The two methods are completely equal the sum or difference of assessment as well. By comparing three uncertainty calculation method, all of the method can be used in evaluating combined standard uncertainty, and the error is within reasonable limits. But every method has advantages and disadvantages, only if different calculation models are used for different issues suitably, will uncertainty evaluation work processes can be greatly simplified.

\section{CONCLUSIONS}

Based on the relevant literature, the procedure of uncertainty assessment is described, including the establishment of uncertainty model, type A or type B of uncertainty assessment, the calculation of combined standard uncertainty and expanded uncertainty, and so on. By solving sensitivity coefficients partial differential formula, two new calculation models of the combined standard uncertainty are proposed. In this way, there is no need solving sensitivity factor directly, and the average error of the two models is within reasonable limits. Therefore, the two models can be used to assess the combined standard uncertainty. If the appropriate model is used for assessing uncertainty of specific issues, it may greatly simplify the uncertainty evaluation workload.

\section{REFERENCES}

[1] Mingyao Xiao. The Error Theory and Application [M]. Beijing: Chinese Metrology Press, 1995 (in Chinese).

[2] Pan Jianguo, Cao Jiangmin. Study on techniques for online measurement to air and pulverized coal mixture flow parameters of coal-fired boiler in power plant [J]. Proceedings of the CSEE, 2004, 24(10):193-195(in Chinese).

[3] Guide to the Expression of Uncertainty in Measurement (GUM) [S].

[4] Zhimin Liu. Uncertainty and Its Practice [M].Beijing: Standards Press of China, 2000(in Chinese).

[5] JJF1059-1999, Evaluation and Expression of Uncertainty in Measurement [S] (in Chinese).

[6] Wang Zhi-guo, Ma Yi-tai, Lu Wei. The Application of Uncertainty Analysis Theory in Thermal Efficiency Testing for Boiler [J]. Proceedings of the CSEE, 2005, 25(3):125-129(in Chinese).

[7] Song Da-yong, DAI Ling, LENG Jie. Uncertainty Analysis of Measuring on Boiler Performance Test [J]. Northeast Electric Power Technology, 2007, 28(2): 30-32(in Chinese).

[8] Quangui Fan, Weiping Yan, Sunlin Yan, Jun Wang. The Principle of Boiler [M]. Beijing: China Electric Power Press, 2008.

[9] Hongkai Liao, Li Wang. Utility Boiler Test [M]. Beijing: China Electric Power Press, 2007 